\title{
PERCEPÇÃO DA POPULAÇÃO SOBRE O CONFORTO TÉRMICO PROPORCIONADO PELA ARBORIZAÇÃO DE RUAS DE CURITIBA-PR
}

\author{
Angeline Martini ${ }^{1}$, Daniela Biondi ${ }^{2}$, Antonio Carlos Batista ${ }^{3}$, Kendra Zamproni ${ }^{4}$, Jennifer Viezzer ${ }^{1}$, \\ Mayssa Mascarenhas Grise ${ }^{5}$, Everaldo Marques Lima Neto ${ }^{6}$ \\ ${ }^{1} E^{2} g^{a}$. Florestal, M.Sc., UFPR, Curitiba, PR, Brasil - martini.angeline@gmail.com; jeviezzer@yahoo.com.br \\ ${ }^{2} \mathrm{Eng}^{\mathrm{a}}$. Florestal, Dra ${ }^{\mathrm{a}}$., Depto. Ciências Florestais, UFPR, Curitiba, PR, Brasil - dbiondi@ufpr.br \\ ${ }^{3}$ Eng. Florestal, Dr., Depto. Ciências Florestais, UFPR, Curitiba, PR, Brasil - batistaufpr@ufpr.br \\ ${ }^{4}$ Acadêmica de Eng. Florestal, UFPR, Curitiba, PR, Brasil - kendra.zam@ gmail.com \\ ${ }^{5}$ Bióloga, M.Sc., UFPR, Curitiba, PR, Brasil - mayssagrise@ibest.com.br \\ ${ }^{6}$ Eng. Florestal, M.Sc., Depto. Ciências Exatas e Agrárias, UERR, Rorainópolis, RR, Brasil - everaldo.limaneto@gmail.com
}

Recebido para publicação: 30/04/2013 - Aceito para publicação: 12/03/2014

\begin{abstract}
Resumo
O objetivo deste artigo foi analisar a percepção da população com relação ao conforto térmico proporcionado pela arborização de ruas na cidade de Curitiba. Para isso foram realizadas entrevistas simultaneamente em uma rua arborizada e outra sem arborização, nas quatro estações do ano. Paralelamente, foram também coletados dados meteorológicos para calcular o índice de conforto térmico nesses ambientes. O índice utilizado foi o Universal Thermal Climate Index (UTCI) e o seu valor foi comparado com a resposta dada pelos entrevistados. A porcentagem de pessoas que declaram não estar sentindo nem frio e nem calor na rua arborizada foi menor do que na rua sem arborização, possivelmente devido ao maior número de entrevistados na primavera e outono, estações com características climáticas amenas. Dos entrevistados, 54,3\% sentiam-se confortáveis termicamente nas ruas sem árvores, enquanto que na rua arborizada esse número foi $76,5 \%$. A maioria dos entrevistados $(98,3 \%)$ afirmou que arborização de ruas proporciona melhores condições de conforto térmico. O índice utilizado, UTCI, refletiu aproximadamente $60 \%$ da sensação de conforto expressa pelos entrevistados. Conclui-se que a população que transita pelas ruas da cidade de Curitiba consegue perceber a diferença entre as ruas arborizadas e não arborizadas por meio das sensações de conforto térmico.

Palavras-chave: Arborização urbana; índice de conforto térmico; qualidade de vida; UTCI.
\end{abstract}

\begin{abstract}
Population's perception on thermal comfort provided by street trees of Curitiba - PR. This research aims to analyze the population's perception regarding thermal comfort provided by street trees in the city of Curitiba. Therefore, interviews were conducted simultaneously on streets with and without trees, during the four seasons. At the same time, meteorological data were collected to calculate the thermal comfort index for these environments. The Universal Thermal Climate Index (UTCI) was used and its value was compared to the answers given in the interviews. The amount of people who said they were not feeling neither cold nor heat on the streets with trees was lower than on the streets without trees, possibly due to a greater number of people who were interviewed during spring and fall, seasons with mild climatic characteristics. While $54.3 \%$ of the people felt comfortable in the streets without trees, $76.5 \%$ felt the same on streets with trees. Most interviewee (98.3\%) said that street trees provide better thermal comfort. The UTCI revealed approximately $60 \%$ of the comfort sense expressed by the population. We concluded that the population who roam the streets of the city of Curitiba - PR can perceive the difference between streets with and without trees through the sensations of thermal comfort.

Keywords: Urban forestry; thermal comfort index; quality of life; UTCI.
\end{abstract}

\section{INTRODUÇÃO}

O processo de crescimento urbano acelerado e desorganizado tem desencadeado uma diversidade de impactos ambientais como reflexo à ocupação e às atividades antrópicas sobre o ambiente, dentre os 
quais se destaca a alteração do clima urbano (NASCIMENTO; OLIVEIRA, 2011).

A falta de vegetação é um dos principais responsáveis pelas alterações do clima nos grandes centros urbanos, uma vez que as propriedades de regulação e melhoria do clima que as árvores oferecem são uma característica fundamental para garantir um clima urbano ideal (ABREU, 2008). Conforme Silva (2009), a influência da vegetação se manifesta nas mais variadas escalas climáticas, porém, para a configuração urbana de um lugar, o clima urbano tem na escala microclimática seu principal grau de interferência. A presença da vegetação nas áreas urbanas cria um microclima que difere daquele das áreas não vegetadas (LIMA, 2009).

Segundo Biondi e Althaus (2005), nas cidades, a temperatura média anual, a velocidade do vento, a nebulosidade, os contaminantes e a precipitação são sempre mais altos do que nos arredores, devido principalmente à estrutura diversificada. Dessa forma, a presença de vegetação nas cidades é essencial na estrutura e dinâmica da paisagem urbana, pois, devido às suas características, melhora a qualidade de vida da população e a condição ambiental das cidades (LIMA NETO, 2011). Torna-se ainda um dos componentes bióticos mais importantes do meio urbano porque está diretamente relacionado com o conforto ambiental (BIONDI, 2008).

As árvores exercem um papel vital para o bem-estar das comunidades urbanas. Sua capacidade única de controlar muitos dos efeitos adversos do meio urbano contribui para uma significativa melhoria da qualidade de vida (VOLPE-FILIK et al., 2007). Porém, conforme Silva (2009), os espaços vegetados dentro das cidades estão concentrados em grandes parques urbanos, sendo deixado de lado o tecido urbano para a implantação da arborização, o que gera um sistema viário empobrecido ambientalmente e desconfortável climaticamente.

Conforme Martini (2011), é cada vez mais difícil encontrar nas cidades espaços para a criação de áreas verdes, devido à competição com os equipamentos urbanos. Por isso, as árvores plantadas ao longo das ruas que formam a arborização viária são uma alternativa na busca pelo bem-estar da população. Além disso, na maioria das cidades brasileiras não existem ações que visem a arborização urbana de forma estruturada, que insiram a vegetação nas vias públicas de forma a buscar microclimas mais confortáveis termicamente (SILVA, 2009).

Sabe-se, ainda, que os benefícios gerados são mais eficientes quando a arborização de ruas é devidamente planejada, considerando-se as características locais, as características das espécies, o planejamento do plantio e a manutenção e monitoramento das árvores (BIONDI; ALTHAUS, 2005). Assim, o conhecimento do comportamento das espécies em relação ao microclima é importante para os planejadores e pesquisadores do ambiente construído, para que sejam incorporados no planejamento ou nas intervenções dos espaços abertos, aproveitando-se com inteligência os benefícios dos indivíduos arbóreos, visando a melhoria da qualidade de vida das pessoas (ABREU; LABAKI, 2010).

Vários trabalhos estão sendo desenvolvidos para melhor entender os ambientes urbanos e sugerir um planejamento adequado para o crescimento, de modo que o cidadão possa ter condições de bem-estar e que o impacto ao ambiente seja o menor possível (KRAN, 2005). Alguns trabalhos que abordam questões sobre o conforto térmico em espaços urbanos estão sendo realizados com a utilização do UTCI, como Novak (2013) na República Tcheca, Milewski (2013) na Polônia, Abdel-Ghany et al. (2013) na Arábia Saudita, Bauche et al. (2013) na Rússia e Mazon (2013) na Espanha. No Brasil, Nince et al. (2013) utilizaram o UTCI na avaliação do conforto termal do Campus da Universidade Federal do Mato Grosso, em Cuiabá, e Rossi et al. (2012) na definição de faixas de conforto e desconforto térmico para espaços abertos de Curitiba.

Nesse contexto, vale ressaltar também a importância de se analisar a percepção das pessoas, que consiste basicamente no contato do indivíduo com seu ambiente de estímulo. O indivíduo, quando inserido em uma realidade e motivado por algum desejo ou vontade, ao entrar em contato com os estímulos através das sensações e experiências anteriores, responde a essa realidade (BASTARZ, 2009). Dessa forma, a aplicação de um índice de conforto térmico já existente e amplamente difundido pode não exprimir a realidade local, visto que outros fatores podem influenciar na sensação térmica e portanto devem ser considerados. Sendo assim, o objetivo desta pesquisa foi analisar a percepção da população com relação ao conforto térmico proporcionado pela arborização de ruas na cidade de Curitiba.

\section{MATERIAL E MÉTODOS}

A pesquisa foi desenvolvida na cidade de Curitiba, localizada no Primeiro Planalto Paranaense, a 934,6 m de altitude média. O marco zero da cidade está localizado na Praça Tiradentes, na latitude $25^{\circ} 25^{\prime} 40^{\prime \prime} \mathrm{S}$ e longitude $49^{\circ} 16^{\prime} 23^{\prime \prime} \mathrm{W}$. Tendo-se por referência a classificação de Köppen, a cidade 
localiza-se em região climática do tipo $\mathrm{Cfb}$, subtropical úmido, mesotérmico, sem estação seca, com verões frescos e invernos com geadas frequentes (INSTITUTO DE PESQUISA E PLANEJAMENTO URBANO DE CURITIBA (IPPUC), 2011).

Foram estabelecidas três amostras na cidade de Curitiba, denominadas: Alto da Rua XV, Hugo Lange e Bacacheri. Cada amostra apresenta um trecho de rua arborizada próximo a um trecho de rua sem arborização (Figura 1).

A amostra Alto da Rua XV é formada por um trecho da Rua Marechal Deodoro (sem arborização) e da Rua Fernando Amaro (arborizado com Tipuana tipu). A amostra Hugo Lange é formada por um trecho da Rua Augusto Stresser (sem arborização) e da Rua Dr. Goulin (arborizada com Handroanthus chrysotrichus). A amostra Bacacheri é formada por um trecho da Rua Estados Unidos (sem arborização) e outro arborizado com Lafoensia pacari e Parapiptadenia rigida.

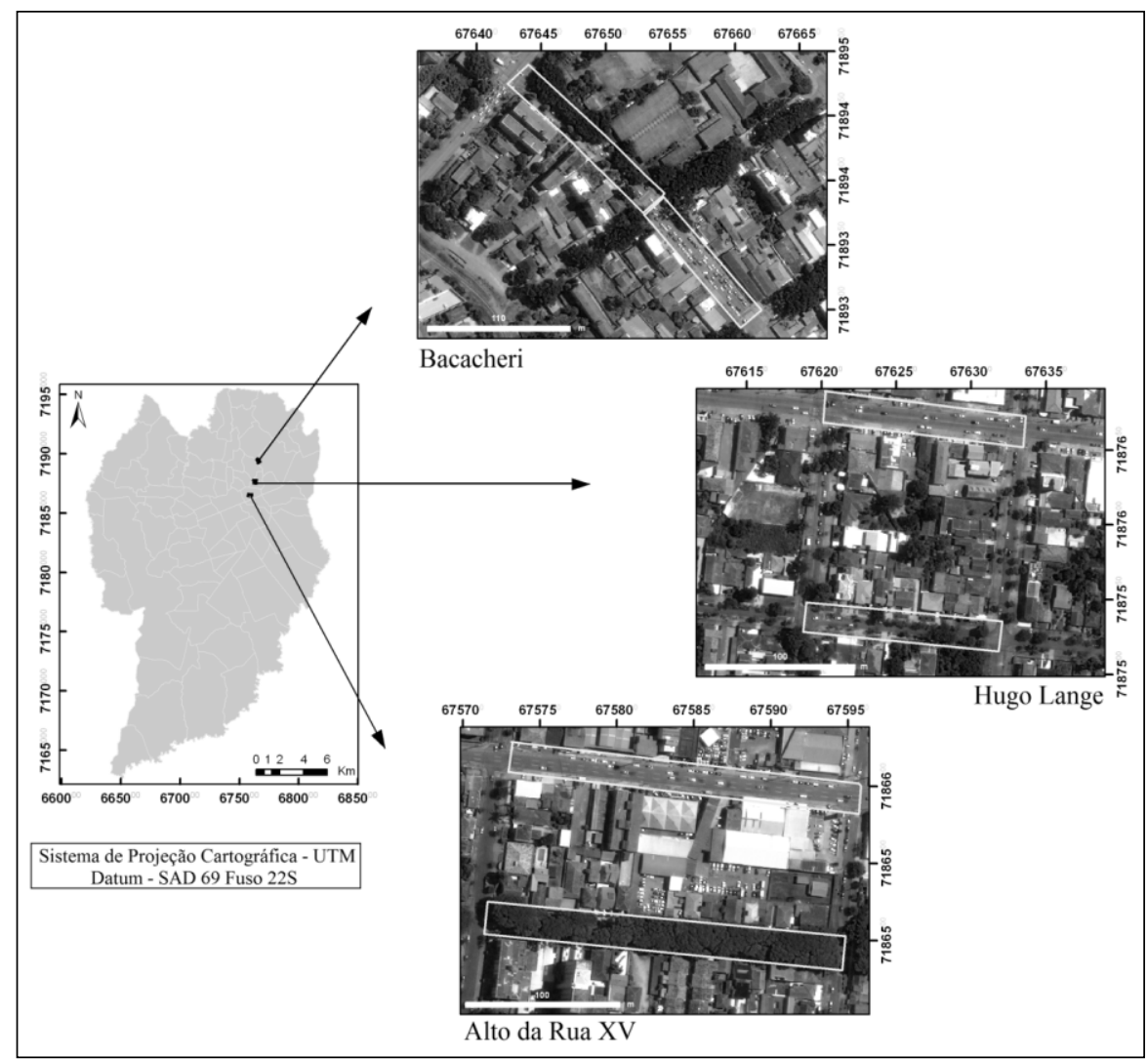

Figura 1. Localização das amostras de estudo na cidade de Curitiba-PR.

Figure 1. Location of the study samples in Curitiba-PR.

As ruas de cada amostra foram selecionadas buscando-se características semelhantes para diminuir as interferências urbanas. Na amostra Alto da Rua XV e Hugo Lange, as ruas apresentam sentido leste-oeste e largura de 18 e $20 \mathrm{~m}$, respectivamente. Ambas as amostras abrigam estabelecimentos comerciais e residenciais em sua maioria, com recuo frontal e construção de apenas um piso, podendo-se encontrar exceções de até quatro pisos. As calçadas são revestidas com placas de concreto ou pedra-lousa e a pista de rolamento é asfaltada. Já a rua Estados Unidos, da amostra Bacacheri, tem sentido sudestenordeste e também apresenta $20 \mathrm{~m}$ de largura. Abriga estabelecimentos, em sua maioria, comerciais com recuo frontal e de apenas um piso, mas pode-se encontrar exceções de até dois pisos. As calçadas são revestidas com placas de concreto ou pedra-lousa e a pista de rolamento também é asfaltada.

A percepção da população com relação ao conforto térmico proporcionado pela arborização de ruas foi avaliada através de entrevistas realizadas simultaneamente em uma rua arborizada e em outra sem arborização (da mesma amostra), seguindo um roteiro elaborado com perguntas objetivas dirigidas às 
pessoas que transitavam nesses ambientes. As entrevistas foram realizadas nas quatro estações do ano, para melhor caracterizar a sensação de conforto térmico na cidade.

Os parâmetros levantados no questionário, relacionados com gênero, altura, massa corporal, idade, vestimenta e atividade realizada, tinham o objetivo de caracterizar a população entrevistada. Os parâmetros subjetivos, sensações térmicas e preferências térmicas foram utilizados para validar a confiabilidade do índice aplicado. A vestimenta ou isolamento térmico proporcionado pela roupa foi calculado em clo, tendo como base os valores tabelados fornecidos pela ISO 7730 (1994).

As escalas de conforto adotadas para coletar informações sobre sensações e preferências térmicas dos usuários foram as mesmas utilizadas por Lyra (2007) e consistem em uma tradução da escala de sete pontos sugeridos pelo Predict Mean Vote (PMV) descritas na ISO 1055 (1995), apresentados na tabela 1. O PMV é um índice desenvolvido para verificar se determinado ambiente encontra-se em condições de aceitabilidade térmica (LAMBERTS; XAVIER, 2002).

Tabela 1. Escala de sensação e preferência térmica sugerida pelo PMV.

Table 1. Thermal sensation and preference scale suggested by PMV.

\begin{tabular}{lccc}
\hline Sensação térmica & & Preferência térmica & +3 \\
\hline Muito calor & +3 & Muito mais quente & +2 \\
Calor & +2 & Mais quente & +2 \\
Pouco calor & +1 & Um pouco mais quente & +1 \\
Nem frio, nem calor & 0 & Nem um nem outro & 0 \\
Pouco frio & -1 & Pouco mais frio & -1 \\
Frio & -2 & Mais frio & -2 \\
Muito frio & -3 & Muito mais frio & -3 \\
\hline
\end{tabular}

Fonte: Lyra (2007).

Outras questões que poderiam facilitar e contribuir com a análise dos resultados incluídas no questionário foram: "em relação ao ambiente, você está se sentindo confortável ou desconfortável?"; "você se classifica como friorento, calorento ou nenhum?"; "quanto tempo está aqui?"; "você acha que uma rua arborizada proporciona um ambiente mais agradável/confortável termicamente?".

Para maior confiabilidade da pesquisa, optou-se também por realizar coletas de dados meteorológicos simultaneamente nas ruas arborizadas e sem arborização, para calcular o índice de conforto térmico nesses ambientes. Assim, as respostas dadas pelos entrevistados sobre a sensação de conforto puderam ser comparadas com valor do índice gerado naquele mesmo momento.

Na coleta dos dados meteorológicos, foram utilizadas duas miniestações da marca Kestrel ${ }^{\circledR}$ e dois "medidores de stress térmico", modelo TGD-400, mantidos a $1,50 \mathrm{~m}$ de altura. As variáveis meteorológicas utilizadas foram: temperatura do ar $\left({ }^{\circ} \mathrm{C}\right)$, umidade relativa $(\%)$, velocidade do vento $(\mathrm{m} / \mathrm{s})$ e temperatura do globo $\left({ }^{\circ} \mathrm{C}\right)$. O monitoramento foi realizado nas quatro estações do ano, com início no inverno de 2011. Os dados foram registrados a cada minuto por um período de 6 horas, das 9 às $15 \mathrm{~h}$ (horário de Brasília), sendo corrigido para 10 às 16 horas no horário de verão. Em cada estação foram realizados três dias de coletas, característicos da estação a que pertencem, um dia para cada amostra.

A influência da arborização de ruas no conforto térmico foi analisada através do Universal Thermal Climate Index (UTCI), índice desenvolvido na Europa e que tem sido amplamente adotado em avaliações referentes ao conforto térmico em ambientes externos. Rossi (2012), utilizou o UTCI na cidade de Curitiba, por se tratar de um dos índices de conforto térmico mais recentes. Ele constatou que o UTCI dentre os demais índices utilizados, foi o que apresentou as menores diferenças entre as respostas reais e as preditas pelos entrevistados.

Esse índice foi calculado a cada minuto, através do programa Bioklima 2.6, software de livre acesso desenvolvido por Michael Blazejczyk (INSTYTUT GEOGRAFII I PRZESTRZENNEGO ZAGOSPODAROWANIA (IGPZ), 2012). Os dados de entrada para o cálculo foram: velocidade do vento a $1,5 \mathrm{~m}$ e a $10 \mathrm{~m}$ de altura do solo, temperatura do ar, umidade relativa e temperatura radiante média.

A velocidade do vento a $10 \mathrm{~m}$ de altura é uma variável fundamental para o cálculo do índice. No entanto, como o monitoramento da variável vento foi realizado a $1,5 \mathrm{~m}$, foi necessário aplicar um fator de escala para a determinação dessa variável (BRÖDE et al., 2012): 


$$
\mathrm{va}=\mathrm{va}_{\mathrm{xm}} \times \log \left(\frac{10}{0,01}\right) \div \log \left(\frac{\mathrm{x}}{0,01}\right)
$$

em que: va = velocidade do vento a $10 \mathrm{~m}$ de altura, $\mathrm{em} \mathrm{m} / \mathrm{s}$;

$\mathrm{va}_{\mathrm{xm}}=$ velocidade do vento medida a $\mathrm{x}$ metros, em $\mathrm{m} / \mathrm{s}$;

$\mathrm{x}=$ altura na qual a velocidade do vento foi medida, neste caso a 1,5 $\mathrm{m}$.

A temperatura radiante média também foi calculada. Para isto, utilizou-se a fórmula definida pela ISO 7726 (1998) para convecção forçada:

$$
\mathrm{T}_{\mathrm{rm}}=\left[(\operatorname{tg}+273)^{4}+2,5 \times 10^{8} \times \mathrm{v}_{\mathrm{a}} 0,6 \times(\text { tg-ta })\right]^{\frac{1}{4}}-273
$$

em que: $\mathrm{T}_{\mathrm{rm}}=$ temperatura média radiante $\left({ }^{\circ} \mathrm{C}\right)$;

$\operatorname{tg}=$ temperatura do globo $\left({ }^{\circ} \mathrm{C}\right)$;

$\mathrm{v}_{\mathrm{a}}=$ velocidade do vento $(\mathrm{m} / \mathrm{s})$;

ta $=$ temperatura do $\operatorname{ar}\left({ }^{\circ} \mathrm{C}\right)$.

Realizados os ajustes e demais cálculos necessários, obteve-se o UTCI para cada conjunto de dados. Esses valores foram classificados em suas respectivas classes de estresse térmico. Dessa forma, a resposta dada pelo entrevistado sobre a sensação de conforto foi comparada com valor de UTCI gerado naquele mesmo momento, uma vez que a hora em que se realizou a entrevista foi anotada. Como as escalas de conforto sugeridas no questionário (sete níveis) e as escalas do UTCI (dez níveis) são diferentes, realizou-se um ajuste (Tabela 2).

Tabela 2. Classes e nível de estresse térmico do UTCI e o ajuste realizado para comparar a sensação térmica dos entrevistados.

Table 2. UTCI categorized in terms of thermal stress and the adjustment made to compare the thermal

\begin{tabular}{|c|c|c|}
\hline \multicolumn{2}{|r|}{ UTCI } & \multirow{2}{*}{ Sensação térmica dos entrevistados } \\
\hline Classes & Nível de estresse térmico & \\
\hline \multirow{10}{*}{$\begin{array}{l}-40^{\circ} \mathrm{C} \\
-27^{\circ} \mathrm{C} \\
-13^{\circ} \mathrm{C} \\
0{ }^{\circ} \mathrm{C} \\
9{ }^{\circ} \mathrm{C} \\
26^{\circ} \mathrm{C} \\
32^{\circ} \mathrm{C} \\
38^{\circ} \mathrm{C} \\
46^{\circ} \mathrm{C}\end{array}$} & Extremo estresse para o frio & \multirow{3}{*}{ Muito frio } \\
\hline & Muito forte estresse para o frio & \\
\hline & Forte estresse para o frio & \\
\hline & Moderado estresse para o frio & Frio \\
\hline & Pouco estresse para o frio & Pouco frio \\
\hline & Sem estresse térmico (conforto) & Nem frio, nem calor (conforto) \\
\hline & Moderado estresse para o calor & Pouco calor \\
\hline & Forte estresse para o calor & Calor \\
\hline & Muito forte estresse para o calor & \multirow{2}{*}{ Muito calor } \\
\hline & Extremo estresse para o calor & \\
\hline
\end{tabular}
sensation of respondents.

No ajuste realizado, igualou-se a classe de conforto de ambas as escalas e as classes extremas do questionário passaram a abranger mais de uma classe gerada pelo UTCI. A partir desse ajuste, se determinou a porcentagem de acertos e aplicou-se a análise de correlação de Spearman. Para diminuir o erro proporcionado pela subjetividade das respostas, optou-se por dividir ambas as escalas apenas em três níveis: conforto térmico, estresse térmico para o calor e estresse térmico para o frio. Para essa nova classificação, também se verificou a porcentagem de acertos.

\section{RESULTADOS E DISCUSSÃO}

Ao longo de todo o período de coleta dos dados meteorológicos, foram entrevistadas 175 pessoas. Esse número reflete o baixo tráfego de pedestres nas ruas estudadas. Uma vez que só era 
possível entrevistar as pessoas que passavam pelos locais durante o período de coleta, por esse motivo também o número de pessoas entrevistadas foi diferente entre as ruas arborizadas e sem arborização e entre as estações do ano.

Nas estações de verão e inverno, que apresentaram os dias mais quentes e frios do período de estudo, o número de pessoas que transitavam pelas ruas foi visivelmente inferior. Também foi possível notar que as ruas arborizadas, exclusivamente residenciais, apresentavam menor fluxo de transeuntes. Assim, foram entrevistadas 94 pessoas nas ruas sem arborização e 81 pessoas nas ruas arborizadas, no inverno foram entrevistadas 30 pessoas, na primavera 55, no verão 38 e no outono 53. Destas, foram obtidos os seguintes resultados:

a) $52,6 \%$ pertencem ao gênero feminino;

b) a média de idade, altura e massa corpórea foram semelhantes entre os dois gêneros: 36 anos, 1,71 metros e $69 \mathrm{~kg}$; o isolamento térmico proporcionado pela vestimenta resultou em uma média de 0,9 clo;

c) a maioria das pessoas entrevistadas estava caminhando antes de responder o questionário (58,9\%);

d) com relação à suscetibilidade térmica, 30,3\% responderam que são mais suscetíveis ao frio e 17,7\% ao calor; os outros $52,0 \%$ não se consideram suscetíveis mais a um do que ao outro.

A sensação térmica sentida no momento da entrevista e a sensação térmica que os entrevistados gostariam de estar sentindo no momento da entrevista foram analisadas paralelamente entre a rua arborizada e sem arborização (Figura 2). Rossi (2012) utilizou o cruzamento das respostas de percepção e de preferência para definir as categorias de sensação térmica, pois somente a percepção térmica não foi suficiente para classificar um indivíduo em uma das categorias propostas. A autora considerou que cada pessoa avalia o ambiente térmico de forma diferente e que os fatores psicológicos e fisiológicos influenciam essa avaliação, motivo pelo qual o cruzamento dos votos de percepção e preferência é a forma mais adequada de classificar as pessoas em cada uma das categorias de sensação térmica.

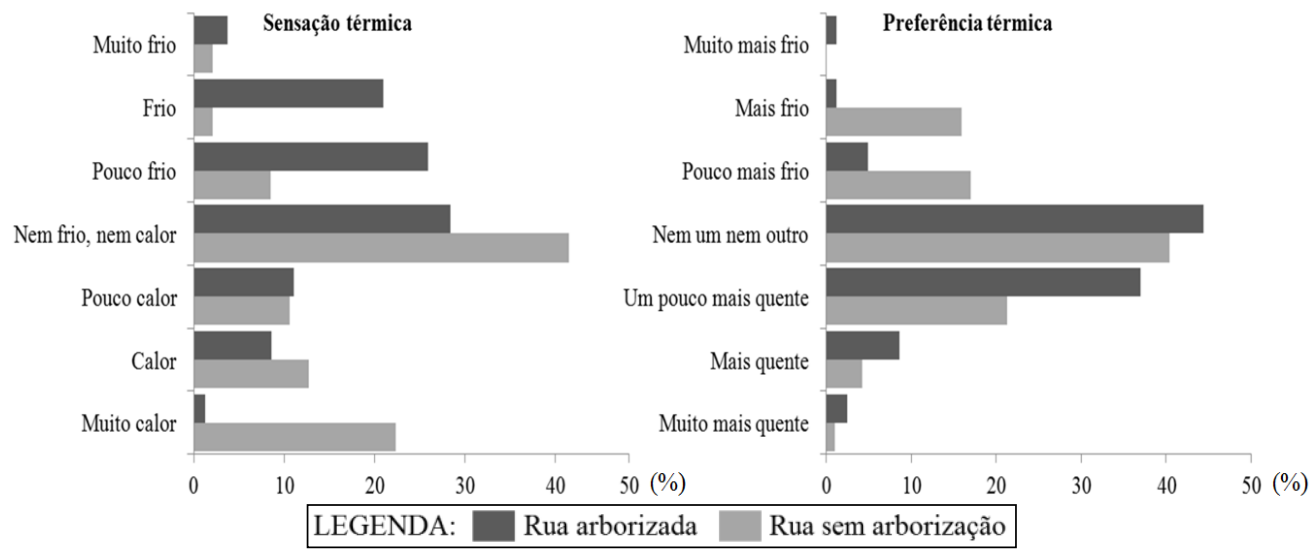

Figura 2. Porcentagem de sensação térmica informada no momento da entrevista e porcentagem de preferência térmica.

Figure 2. Thermal sensation percentage informed at the interview and percentage of thermal preference.

Observa-se que a porcentagem de pessoas que declaram não estar sentindo nem frio e nem calor na rua arborizada $(28,4 \%)$ foi menor do que na rua sem arborização $(41,5 \%)$. As respostas na rua arborizada, em sua maioria estiveram nas classes de desconforto para o frio (muito frio, frio e pouco frio), enquanto que nas ruas sem arborização foram maiores as proporções nas classes de desconforto para o calor (pouco calor, calor, muito calor). Esse resultado pode ser explicado pela diferença do número de entrevistados entre as ruas e estações do ano. A maioria das entrevistas foi realizada na primavera e no outono, estações com características climáticas menos acentuadas do que verão e inverno. Assim, a influência provocada pela vegetação pode não ter sido sentida tão claramente.

As pessoas de maneira geral percebem o microclima dos ambientes vegetados como mais frescos e úmidos do que as condições de tempo na ambiência urbana (DACANAL et al., 2010), resultado das 
condições microclimáticas proporcionadas pela vegetação, já discutidas anteriormente, principalmente o fato de os menores valores de temperaturas terem sido encontrados na rua arborizada. Lima et al. (2009), em pesquisa similar realizada em Maringá, concluíram que grande parte dos entrevistados sentiu neutralidade térmica próxima às áreas com maior densidade de vegetação.

A sensação térmica "nem frio e nem calor" foi maior na rua sem arborização, o que não era esperado. Esse resultado contraria inclusive as respostas dadas à pergunta sobre como os entrevistados gostariam de estar se sentindo naquele momento. Destaca-se que o maior número de entrevistados satisfeitos com a sensação térmica, ou seja, que não queriam nem que o ambiente estivesse mais quente nem mais frio, foi encontrado na rua arborizada $(44,4 \%)$. Fazendo correspondência com a pergunta anterior, os resultados mostram que $48 \%$ dos entrevistados na rua arborizada gostariam que o ambiente estivesse mais quente (entende-se aqui todas as classes, "um pouco mais quente", "mais quente" e "muito mais quente"), enquanto que 33\% dos entrevistados na rua sem arborização gostariam de um ambiente mais frio ("muito mais frio", "mais frio" e "pouco mais frio").

Essas contradições geradas podem ser decorrentes de diversos fatores, entre os quais podem estar os efeitos psicológicos que o ambiente agradável ou não provoca nos usuários, como é o caso de um espaço arborizado (LIMA et al., 2009). Segundo Dacanal et al. (2010), a percepção ambiental, que consiste na consciência das sensações advindas da interação entre o homem e o espaço, ocorre de maneira individualizada, visto que depende das experiências anteriores relacionadas às informações sensoriais, culturais e outras armazenadas na memória. Portanto, a percepção do microclima varia de acordo com as experiências climáticas já vividas pelo indivíduo e ocorre comparando-se o presente (espaço e tempo em que o corpo está presente) ao passado (mesmo espaço, porém em um tempo anterior) e a outros espaços (o aqui e o ali).

Nikolopoulou e Steemers (2003) afirmam que as pessoas adaptam-se psicologicamente em função da exposição repetida a um mesmo estímulo e constroem esquemas mentais que auxiliam na escolha de ações sob diferentes circunstâncias. Logo, se considerar que a avaliação do conforto térmico está relacionada a fatores fisiológicos e psicológicos e que as condições ambientais requeridas para o conforto térmico não são as mesmas para todos, é possível que uma pessoa que esteja sentindo algum grau de calor ou de frio declare estar confortável e aceite o ambiente térmico em questão (ROSSI, 2012). Da mesma forma, a autora afirma ser possível que uma pessoa que declare estar em conforto prefira estar em um ambiente termicamente diferente.

A subjetividade das questões também pode ter sido fonte dessas variações, pois durante a aplicação dos questionários já era notada a dificuldade por parte dos entrevistados em se enquadrar nas classes de desconforto. Segundo Tuan (2012), os seres humanos têm uma tendência para estruturar sua percepção em um número limitado de categorias, sendo que a ordenação detalhada dos componentes varia muito de cultura para cultura. Assim, as categorias simples baseadas nas opiniões binárias, com um ponto mediador, integram um esquema de complexidade adequado. Também é provável que as categorias mais simples sejam uma tentativa posterior para explicar as riquezas incipientes de uma estrutura anterior.

Rossi (2012) também encontrou dificuldades de entendimento por parte dos respondentes. Ao utilizar a escala de sete pontos para as questões de percepção e de preferência térmica, verificou que a maior parte das respostas se concentrou nos votos $-1,0$ e 1, enquanto para os demais votos a quantidade de respostas obtidas foi pequena, não sendo possível considerar esses votos como categorias separadas para análise.

Por esses motivos, pode-se afirmar que o simples fato de perguntar se o entrevistado estava se sentindo confortável ou desconfortável em relação ao ambiente tenha sido a melhor forma de comparar a sensação de conforto proporcionado pelas diferentes ruas. Com essa pergunta, foi verificado que 54,3\% dos entrevistados sentiam-se confortáveis termicamente nas ruas sem árvores, enquanto que na rua arborizada esse número foi de 76,5\%. De maneira inversa, verificou-se $45,7 \%$ dos entrevistados em desconforto na rua sem arborização e $23,5 \%$ na rua arborizada, o que demonstra que as ruas arborizadas apresentam melhores condições de conforto térmico, embora haja contradições de caráter pessoal. Os resultados encontrados através da aplicação de questionários indicaram que a arborização de ruas proporciona melhores condições de conforto térmico. Opinião apontada também por $98,3 \%$ dos entrevistados.

A análise de correlação de Spearman aplicada entre a sensação térmica informada pelos entrevistados e a classe de estresse térmico obtida com o UTCI resultou em um coeficiente de 0,78. Resultado que indica uma forte correlação entre a sensação térmica informada pelos entrevistados e a classe de estresse obtida com o UTCI. Em estudos já realizados na cidade de Curitiba, Rossi et al. (2012) já comprovaram a eficácia do índice UTCI na predição de graus de conforto e desconforto térmico.

Ao analisar separadamente as sete classes de conforto, verificou-se que $43,4 \%$ das respostas dadas pelos entrevistados foram iguais à sensação predita pelo UTCI, sendo que o índice subestimou a 
sensação de conforto em $19,4 \%$ dos casos e superestimou em $37,1 \%$. As subestimativas foram de $17,1 \%$ para uma classe logo abaixo e de 2,3\% para duas classes abaixo. Já as superestimativas foram de 21,7\% para uma classe acima, $13,7 \%$ para duas, $1,1 \%$ para três e $0,6 \%$ para quatro.

Rossi (2012), observando concentração de votos nas classes próximas umas das outras, optou por classificar a sensação térmica em três categorias: desconforto para o frio, conforto e desconforto para o calor. Assim, na presente pesquisa, considerando-se essas classes gerais, a porcentagem de respostas iguais ao UTCI passa a ser de 58,9\%, com uma superestimativa do índice em $36,0 \%$ e subestimativa de apenas $5,1 \%$. Essa última análise anula tanto o efeito da subjetividade do entrevistado quanto as correções realizadas para ajustar as duas escalas.

Em trabalho realizado para determinar o modelo preditivo para avaliação da sensação térmica em espaços abertos de Curitiba, Rossi (2012) encontrou resultados parecidos entre o UTCI e a sensação térmica real (com base em entrevistas). Ao considerarem a sensação térmica real, obtiveram um maior número de pessoas em conforto $(61,2 \%)$ e uma distribuição equilibrada entre pessoas com desconforto para o frio $(17,2 \%)$ e para o calor $(21,2 \%)$. Com os dados preditos pelo UTCI, verifica-se a mesma situação, mas com valores de $42,6 \%$ para a sensação de conforto, $27,3 \%$ para desconforto para o frio e $30,1 \%$ para desconforto para o calor.

Lima et al. (2009), quando comparam o cálculo do Predict Mean Vote (PMV) com o voto médio declarado, também encontraram uma superestimativa do índice de conforto calculado, observando, por exemplo, que quando o calculado foi "muito quente", o voto médio declarado foi "quente". Segundo Rossi (2012), isso ocorre porque o PMV foi desenvolvido para ambientes internos e por isso seu uso para predizer o conforto em ambiente aberto é generalizado.

Rossi (2012) também constatou que o UTCI subestima a quantidade de pessoas em conforto e superestima a quantidade de pessoas em desconforto tanto para o calor quanto para o frio, assim como os demais índices testados pela autora, PMV e Physiological Equivalent Temperature (PET). Mesmo assim, dos três índices testados, o UTCI foi o que apresentou as menores diferenças entre as respostas reais e as preditas para as três categorias de conforto. A autora afirma que essa diferença encontrada para todos os índices pode ser explicada pelo fato de os índices considerarem somente aspectos fisiológicos e climáticos, enquanto que as respostas reais podem ser influenciadas por aspectos emocionais, psicológicos, socioculturais e adaptativos.

\section{CONCLUSÃO}

- Os resultados encontrados enfatizam a importância da arborização de ruas para a cidade de Curitiba. A população que transita pelas ruas da cidade sente maior conforto térmico quando está em uma rua arborizada. A maior parte das pessoas, quando questionadas diretamente, afirmam que a arborização proporciona um ambiente mais confortável termicamente, demonstrando o alto grau de consciência com relação à importância da arborização para a melhoria microclimática.

- O estudo realizado contribui para subsidiar projetos que visam a melhoria da gestão e planejamento urbano, pois demonstra a opinião da população com relação a fatores que auxiliam na melhoria da sua qualidade de vida.

- O índice de conforto térmico utilizado, UTCI, refletiu aproximadamente $60 \%$ da sensação de conforto expressa pelos entrevistados, demonstrando sua eficiência para a análise do conforto térmico na cidade. Sugere-se que novos trabalhos sejam realizados para aperfeiçoar a utilização do UTCI à realidade das regiões brasileiras, bem como à sua utilização aplicada.

\section{AGRADECIMENTOS}

À Fundação Araucária de Apoio ao Desenvolvimento Científico e Tecnológico do Paraná, pelo financiamento à compra dos equipamentos.

\section{REFERÊNCIAS}

ABDEL-GHANY, A. M.; AL-HELAL, I. M.; SHADY, M. R. Human thermal comfort and heat stress in an outdoor urban arid environment: a case study. Advances in Meteorology, New York, v. 2013, p. 1 - 7, 2013. 
ABREU, L. V. de. Avaliação da escala de influência da vegetação no microclima por diferentes espécies arbóreas. 154 f. Dissertação (Mestrado em Engenharia Civil) - Universidade Estadual de Campinas, Campinas, 2008.

ABREU, L. V.; LABAKI, L. C. Conforto térmico propiciado por algumas espécies arbóreas: avaliação do raio de influência através de diferentes índices de conforto. Ambiente Construído, v. 10, n. 4, p. 103 $117,2010$.

BASTARZ, C. Análise da preferência da paisagem do município de Morretes, Paraná, como subsídio ao planejamento do turismo. 122 f. Dissertação (Mestrado em Engenharia Florestal) Universidade Federal do Paraná, Curitiba, 2009.

BAUCHE, J. P.; GRIGORIEVA, E. A.; MATZARAKIS, A. Human-Biometeorological Assessment of Urban Structures in Extreme Climate Conditions: The Example of Birobidzhan, Russian Far East. Advances in Meteorology, New York, v. 2013, p. 1 - 10, 2013.

BIONDI, D.; ALTHAUS, M. Árvores de rua de Curitiba: cultivo e manejo. Curitiba: FUPEF, 2005. 175 p.

BIONDI, D. Arborização urbana: aplicada à educação ambiental nas escolas. Curitiba, 2008. 120 p.

BLAŻEJCZYK, K.; BRÖDE, P.; FIALA, D.; HAVENITH, G.; HOLMÉR, I.; JENDRITZKY, G.; KAMPMANN, B.; KUNERT, A. Principles of the new Universal Thermal Climate Index (UTCI) and its application to bioclimatic research in european scale. Miscellanea Geographica, Warszawa, v. 14, p. 91 $-102,2010$.

BRÖDE, P.; KRÜGER, E. L.; ROSSI, F. A.; FIALA, D. Predicting urban outdoor thermal comfort by the Universal Thermal Climate Index UTCI - a case study in southern Brazil. International Journal of Biometeorology, Ohio, v. 56, p. 471 - 480, 2012.

DACANAL, C.; LABAKI, L. C.; SILVA, T. M. L. Vamos passear na floresta! O conforto térmico em fragmentos florestais urbanos. Ambiente Construído, Porto Alegre, v. 10, n. 2, p. 115 - 132, 2010.

INSTITUTO DE PESQUISA E PLANEJAMENTO URBANO DE CURITIBA (IPPUC). Desenvolvimento sustentável: indicadores de sustentabilidade de Curitiba - 2010. Curitiba: IPPUC, $2011.77 \mathrm{p}$.

INSTYTUT GEOGRAFII I PRZESTRZENNEGO ZAGOSPODAROWANIA (IGPZ). Bioklima. Disponível em: <http://www.igipz.pan.pl/Bioklima-zgik.html> Acesso em: 18/07/2012.

INTERNACIONAL ORGANIZATION FOR STARDARDIZATION (ISO). Moderate thermal environments - determination of the PMV and PDD indices and specification of the conditions for thermal comfort, ISO 7730. Genebra, 1994.

Ergonomics of the thermal environment - Assessment of the influence of the thermal environment using subjective judgement scales, ISO 10551. Genebra, 1995.

Ergonomics of the thermal environment - Instruments formeasuring physical quantities, ISO 7726. Genebra, 1998.

KRAN, F. S. Qualidade de vida na cidade de Palmas - TO: uma análise através de indicadores habitacionais e ambientais urbanos. 142 f. Dissertação (Mestrado em Ciências do Ambiente) Universidade Federal do Tocantins, Palmas, 2005.

LAMBERTS, R.; XAVIER, A. A. de P. Conforto térmico e stress térmico. Laboratório de Eficiência Energética em Edificações - UFSC, Florianópolis, 2002. Apostila de aula.

LIMA, D. C. R.; NUNES, L. A.; SOARES, P. F. Avaliação da influência da vegetação no conforto térmico em espaços livres. In: SIMPÓSIO DE PÓS-GRADUAÇÃO EM ENGENHARIA URBANA, 2009, Maringá. Anais... Maringá: [s.n.], 2009. Não paginado. 
LIMA, D. C. R. Monitoramento e desempenho da vegetação no conforto térmico em espaços livres urbanos: o caso das praças de Maringá/PR. 170 f. Dissertação (Mestrado em Engenharia Urbana) Departamento de Engenharia Civil, Universidade Estadual de Maringá, Maringá, 2009.

LIMA NETO, E. M. Aplicação do sistema de informações geográficas para o inventário da arborização de ruas de Curitiba, PR. 120 f. Dissertação (Mestrado em Engenharia Florestal) - Setor de Ciências Agrárias, Universidade Federal do Paraná, Curitiba, 2011.

LYRA, D. S. F. M. Aplicabilidade de índices de conforto térmico: um estudo de caso em Salvador BA. 131 f. Dissertação (Mestrado em Engenharia Ambiental Urbana) - Escola Politécnica, Universidade Federal da Bahia, Salvador, 2007.

MARTINI, A. Estudo fenológico em árvores de rua. In: BIONDI, D.; LIMA NETO, E. M. de (Org.). Pesquisas em arborização de ruas. Curitiba, 2011. p. 29 - 48.

MAZON, J. The influence of thermal discomfort on the attention index of teenagers: an experimental evaluation. International Journal of Biometeorology, Ohio, v. feb., 2013.

MILEWSKI, P. Application of the UTCI to the local bioclimate of Poland's Ziemia Kłodzka region. Geographia Polonica, Warszawa, 2013, v. 86, n. 1, p. 47 - 54, 2013.

NASCIMENTO, D. T. F.; OLIVEIRA, I. J. de. Análise da evolução do fenômeno de ilhas de calor no município de Goiânia/GO (1986-2010). Boletim Goiano de Geografia, Goiânia, v. 31, n. 2, p. 113 - 127, 2011.

NIKOLOPOULOU, M.; STEEMERS, K. Thermal comfort and psychological adaptation as a guide for designing urban spaces. Energy and Buildings, Lausanne v. 35, p. 95 - 101, 2003.

NINCE, P. C. C.; MUSIS, C. R.; BIUDES, M. S.; NOGUEIRA, J. S.; NOGUEIRA, M. C. J. A. Usos dos índices PET e UTCI na avaliação do conforto termal no Campus da UFMT em Cuiabá-MT. Revista Eletrônica em Gestão, Educação e Tecnologia Ambiental, v. 9, n. 9, p. 2026 - 2036. 2013.

NOVAK, M. Use of the UTCI in the Czech Republic. Geographia Polonica, Warszawa, v. 86, n. 1, p. 21 $-28,2013$

ROSSI, F. A. Proposição de metodologia e de modelo preditivo para avaliação da sensação térmica em espaços abertos em Curitiba. 188 f. Tese (Doutorado em Tecnologia) - Universidade Tecnológica Federal do Paraná, Curitiba, 2012.

ROSSI, F. A.; KRÜGER, E. L.; BRÖDE, P. Definição de faixas de conforto e desconforto térmico para espaços abertos em Curitiba, PR, com o índice UTCI. Ambiente Construído, Porto Alegre, v. 12, n. 1, p. $41-59,2012$.

SILVA, C. F. Caminhos bioclimáticos: desempenho ambiental de vias públicas na cidade de Terezina, PI. 140 f. Dissertação (Mestrado em Arquitetura e Urbanismo) - Universidade de Brasília, Brasília, 2009.

TUAN, Y. F. Topofilia: um estudo da percepção, atitudes e valores do meio ambiente. Tradução de Lívia de Oliveira. Londrina: Eduel, 2012. 342 p.

VOLPE-FILIK, A.; SILVA, L. F. da; LIMA; A. M. L. P. Avaliação da arborização de ruas do bairro São Dimas na cidade de Piracicaba/SP através de parâmetros qualitativos. Revista da Sociedade Brasileira de Arborização Urbana, Piracicaba, v. 2, n. 1, p. 34 - 43, 2007. 